\title{
Opal diagenesis within Southern Ocean sediments tracked by stable silicon isotopes
}

\author{
IVIA CLOSSET ${ }^{1}$, BRZEZINSKI MARK ${ }^{1}$, DAMIEN \\ CARDINAL $^{2}$, ARNAUD DAPOIGNY ${ }^{3}$, JANICE JONES ${ }^{1}$ \\ AND REBECCA ROBINSON ${ }^{4}$ \\ ${ }^{1} \mathrm{UCSB}$ \\ ${ }^{2}$ University Pierre and Marie Curie, Paris, France \\ ${ }^{3} \mathrm{LSCE}$ \\ ${ }^{4} \mathrm{URI}$
}

Presenting Author: ivia@ucsb.edu

Diatoms are known to fractionate $\mathrm{Si}$ isotopes during the formation of their siliceous frustules causing the $\mathrm{Si}$ isotopic composition of opal $\left(\delta^{30} \mathrm{Si}\right)$ to track the degree of $\mathrm{Si}$ consumption in surface waters. In this context, studies use diatom $\delta^{30} \mathrm{Si}_{\text {opal }}$ preserved in sediment archives to reconstruct past changes in $\mathrm{Si}$ utilization. However, evaluation of how diagenesis of diatoms in marine sediments affects the $\delta^{30} \mathrm{Si}_{\text {opal }}$ preserved in oceanic archives has received little attention.

Porewater silicic acid $\left(\mathrm{Si}_{\mathrm{pw}}\right)$ concentrations and $\delta^{30} \mathrm{Si}_{\mathrm{pw}}$, combined for the first time with those of both opal and clay were measured in five sediment cores in the different zones of the Southern Ocean, and used to decipher early diagenetic processes which would have remained undetected by elemental concentrations alone. The range of $\delta^{30} \mathrm{Si}_{\mathrm{pw}}$ (from +0.20 to $+1.75 \%$ ) closely matched that of $\delta^{30} \mathrm{Si}_{\text {opal }}$ (from +0.38 to $+1.73 \%$ ) suggesting that $\mathrm{Si}_{\mathrm{pw}}$ is primarily derived from the dissolution of opal. This dissolution did not seem to induce a fractionation of $\mathrm{Si}$ isotopes, supporting the use of $\delta^{30} \mathrm{Si}$ of diatoms preserved in the sediments as a proxy for Si utilization in the past ocean. In the Sub-Antarctic Zone, the influence of opal dissolution on $\mathrm{Si}_{\mathrm{pw}}$ is less dominant compared to the other regions with the upper part of the sediment influenced by the intrusion of bottom water and the deeper part of the core influenced by the precipitation of authigenic alumino-silicates. On average precipitation removed $11 \%$ of $\mathrm{Si}_{\mathrm{pw}}$. In contrast, the Polar-Front Zone sediments have experienced some dissolution of isotopically light clay (averaging $-0.18 \pm 0.10 \%$ in our study), with approximately $20 \%$ of the $\mathrm{Si}_{\mathrm{pw}}$ originating from this process. Sediments from the Antarctic Zone showed a $\delta^{30} \mathrm{Si}_{\mathrm{pw}}$ influenced by a combination of both dissolution of clay and precipitation of authigenic alumino-silicates.

Overall $\mathrm{Si}_{\mathrm{pw}}$ concentrations and $\delta^{30} \mathrm{Si}_{\mathrm{pw}}$ signatures of Southern Ocean porewaters are the result of a dynamic balance between the dissolution of opal and reactive clay phases and $\mathrm{Si}$ reprecipitation, the contribution of each processes differing significantly between hydrographic regions. 